\section{Dr. Zotos replies}

\section{To the Editor:}

We thank Drs. Wingerchuk and Weinshenker for their precise comments ${ }^{1}$, which we found extremely interesting. Unfortunately, our patient died one month later due to septic shock. Therefore, our discussion now remains theoretical.

The patient was diagnosed with systemic lupus erythematosus (SLE) 4 years prior to admission to hospital. At the time of diagnosis 6 out of 11 criteria for SLE were fulfilled: malar rash, photosensitivity, arthritis, leukopenia $\left(3200 / \mathrm{mm}^{3}\right)$ and lymphopenia $\left(1000 / \mathrm{mm}^{3}\right)$, anti-DNA and anti-Sm antibodies, and antinuclear antibodies. Since then she was under treatment with hydroxychloroquine $400 \mathrm{mg}$ only. She had not been hospitalized for any reason previously, and this was the first serious attack related to SLE. The cerebrospinal fluid analysis revealed mild pleocytosis $\left(150 / \mathrm{mm}^{3}\right)$ with neutrophilic predominance (80\%), glucose value $75 \mathrm{mg} / \mathrm{dl}$ with simultaneous blood glucose level $130 \mathrm{mg} / \mathrm{dl}$, and protein level of $250 \mathrm{mg} / \mathrm{dl}$. Gram stain and culture of cerebrospinal fluid were negative, as was polymerase chain reaction testing for herpes simplex virus, enteroviruses, and varicella zoster virus. She did not undergo serum testing for neuromyelitis optica
(NMO)-IgG and the brain imaging study was normal, apart from the longitudinal myelitis.

Reviewing the literature upon NMO, we must agree that it is a possible diagnosis for this patient. This clinical entity frankly was not considered in our differential diagnostic procedure at that time. Therefore, NMO-IgG testing was not requested, and obviously this hypothesis can never be confirmed. Considering that NMO syndrome has a relapsing course and characteristically involves optic nerves, our patient had only one attack of the central nervous system and had never complained of visual disturbances.

PANAGIOTIS ZOTOS, MD, Intensive Care Unit, General State Hospital of Athens, Mesogeion 154, Athens, 11527 Greece.

E-mail: pzotos@endo.gr

\section{REFERENCE}

1. Wingerchuk DM, Weinshenker BG. Lupus related longitudinal myelitis [letter]. J Rheumatol 2011;38:1520.

J Rheumatol 2011;38:7; doi:10.3899/jrheum.110046 